\begin{tabular}{|c|l|}
\hline Title & Nondestructive measurement of cross sectional shape of a tree trunk \\
\hline Author(s) & Koizumi, A kio; Ikeda, Keisuke; Sawata, Kei; Hirai, Takuro \\
\hline Citation & $\begin{array}{l}\text { Journal of Wood Science, 57(4), 276-281 } \\
\text { https://doi.org/40.1007/S10086-011-11741 } 1\end{array}$ \\
\hline Issue Date & 2011-08 \\
\hline Doc URL & http://hdl.handle.net/2115/47097 \\
\hline Rights & The original publication is available at www.springerlink.com \\
\hline Type & article (author version) \\
\hline File Information & jws57_4.pdf \\
\hline
\end{tabular}

Instructions for use 


\title{
Nondestructive measurement of cross-sectional shape of a tree trunk
}

\author{
by
}

\author{
Akio Koizumi, Keisuke Ikeda, Kei Sawata, and Takuro Hirai \\ Graduate school of Agriculture, Hokkaido University
}

\begin{abstract}
Key words
nondestructive evaluation, section modulus, windthrow resistance, tree trunk, drill resistance technique
\end{abstract}

\begin{abstract}
To evaluate windthrow resistance with respect to stem breakage, a nondestructive method for determining the shape of a trunk cross section was developed. In this method, the coordinates of multiple gauge points set on the perimeter of a trunk were calculated by measuring the distances between them. The shape between the gauge points was generated with the use of a profile gauge placed between them. The measurement test was conducted using profile gauges with lengths of $300 \mathrm{~mm}$ and $900 \mathrm{~mm}$ on the model specimens, which had 4 shape patterns and 4 diameter sizes. The accuracy of the estimation was verified by comparing the section modulus calculated for the generated image and for the photo image. The average ratio of section modulus (generated/photo) for all specimens was 0.994, which indicate that the proposed method is highly accurate. The section moduli of trunks with inside hollow can be evaluated using the profile method together with the drill resistance technique on the condition that $26 \%$ of the trunk diameter could be drilled without skew.
\end{abstract}

\section{Introduction}

When analyzing windthrow resistance of standing trees, trees can be considered as cantilevered beams that are supported by a root plate in the ground. The load induced by a stormy wind force acting on the tree crown can cause breakage of the trunk or uprooting. Although the common cause of stem breakage is bending failure, shear failure ${ }^{1}$ and shell buckling $^{2}$ also play a role in the case of thin-walled trunks that suffer from heartwood decay. In either case, accurate measurement of the shape of the cross section at a critical height of the trunk is required.

A cross section of the trunks of well-conditioned plantation-grown conifers can be assumed to be circular. However, roadside or park trees are often aged or injured and the cross section of such tree-trunks may be irregular and hollowed. In order to evaluate the moment of inertia and the section modulus of irregular cross sections, a computing method using a binarized image of the shape of a cross section was developed and applied to the estimation of critical wind speed for aged poplar trees with hollow trunks ${ }^{3}$. However, the binarized images 
were converted from photographs of the crosscut surface taken after the trees were felled-a method that is inappropriate for the diagnosis of windthrow hazard. For this reason, this study considers a non-destructive method of measuring the outside shapes of tree trunks that uses a profile gauge.

To perform nondestructive estimation of the distribution of decay or hollowed areas inside trunks, it is possible to apply X-ray-computed tomography ${ }^{4}$. However, the device that was developed for this was not sufficiently portable and thus could not be used for in situ diagnosis ${ }^{5}$. Although computed tomography using stress waves or ultrasonic waves have been developed $^{6}$, the accurate evaluation of sound wood thickness is difficult, especially for trees less than $1 \mathrm{~m}$ in diameter ${ }^{7}$. The thickness of sound sapwood has been measured by a drilling device using a drill resistance technique ${ }^{8}$. Since the diameter of the fine drilling needle is as small as $3 \mathrm{~mm}$, the damage to the tree is considered negligible. This drilling resistance technique has been used for the detection of heartwood decay in park trees ${ }^{7}$ and for the inspection of exterior structures such as wooden bridges 9 .

The purpose of this study was to propose a nondestructive method of estimating the cross-sectional shape of trees for windthrow risk diagnosis.

\section{Materials and methods}

Measurement of outside shape of a trunk using profile method

After establishing the gauge points on the perimeter of a tree trunk in the horizontal plane (points A-E in Fig. 1), the distance from point A to each gauge point and the distance between adjacent points were measured with a caliper. Then the coordinates of the gauge points $(X, Y)$ and the angles of sides from the $X$ axis ( $\beta$ ) were determined. With reference to triangle $\mathrm{ABC}$ in Fig.1, the angles of line $\mathrm{AC}$ from the $X$ axis $(\alpha)$ and line $\mathrm{BC}$ from the $X$ axis $(\beta)$ can be calculated using the height of the triangle $(h)$ with the longest side as the base.

$$
h=\frac{2 A}{\max (a, b, c)}
$$

Where $\quad A=\sqrt{s(s-a)(s-b)(s-c)}, \quad s=\frac{(a+b+c)}{2} \quad$ (Heron's formula) 


$$
\begin{array}{ll}
\alpha= \begin{cases}\sin ^{-1} \frac{h}{c} & a=\max (a, b, c) \\
\pi-\left(\sin ^{-1} \frac{h}{a}+\sin ^{-1} \frac{h}{c}\right) & b=\max (a, b, c) \\
\sin ^{-1} \frac{h}{a} & c=\max (a, b, c)\end{cases} \\
\beta= \begin{cases}\pi-\sin ^{-1} \frac{h}{b} & a=\max (a, b, c) \\
\pi-\sin ^{-1} \frac{h}{a} & b=\max (a, b, c) \\
\pi-\left(\cos ^{-1} \frac{h}{a}+\cos ^{-1} \frac{h}{b}\right) & c=\max (a, b, c)\end{cases}
\end{array}
$$

Then the coordinates of point $\mathrm{C}\left(X_{\mathrm{C}}, Y_{\mathrm{C}}\right)$ can be determined from $\alpha$ and $c$.

$$
\begin{aligned}
& X_{\mathrm{C}}=c \cos \alpha \\
& Y_{\mathrm{C}}=c \sin \alpha
\end{aligned}
$$

$X_{\mathrm{C}}, Y_{\mathrm{C}}$, and $\beta$ in Fig. 1 are expressed by Eqs. 6-8, substituting Eqs. 1 and 2 into Eqs. 4 and 5 and organizing the cases.

$$
\begin{aligned}
& X_{\mathrm{C}}= \begin{cases}-c \cos \left(\sin ^{-1} \frac{2 A}{a b}+\sin ^{-1} \frac{2 A}{b c}\right) & b=\max (a, b, c) \\
c \sqrt{1-\frac{4 A^{2}}{a^{2} c^{2}}} & b \neq \max (a, b, c)\end{cases} \\
& Y_{\mathrm{C}}= \begin{cases}c \sin \left(\sin ^{-1} \frac{2 A}{a b}+\sin ^{-1} \frac{2 A}{b c}\right) & b=\max (a, b, c) \\
\frac{2 A}{a} & b \neq \max (a, b, c)\end{cases} \\
& \beta= \begin{cases}\pi-\left(\cos ^{-1} \frac{2 A}{a c}+\cos ^{-1} \frac{2 A}{b c}\right) & c \neq \max (a, b, c) \\
\pi-\sin ^{-1} \frac{2 A}{a b} & \end{cases}
\end{aligned}
$$


The coordinates for the rest of the gauge points are calculated in the same manner, creating an image with a polygonal shape (Fig. 1). After fitting a profile gauge to each interval between adjacent gauge points, shape-line segments that were extracted from digital photographs of the fitted profile gauge were pasted to the sides of the polygon. An example of the generated outside shape with a polygon and a photograph of a stump cross section are shown in Fig. 2. The xylem cross section can be estimated by subtracting the bark thickness from the outside shape.

Two profile gauges were used in this study, one was a commercially produced gauge with a 300-mm span (needle pitch: $1 \mathrm{~mm}$ ) and the other was made of lumber and aluminum pipes (span: $900 \mathrm{~mm}$, needle pitch: 10mm)(Fig. 3).

Verification of accuracy of outside shape estimation

Although the cross-sectional shapes of tree trunks are regularly circular or oval, aged trees tend to have irregular shape with multiple limbs. Considering the shapes of aged park trees, shape patterns I-IV (Fig. 4) were chosen to verify the accuracy of outside shape estimation. The specimens were cut with a jigsaw from 40-mm-thick side-jointed dimension lumber. Specimens of 4 sizes (300, 600, 900, and $1200 \mathrm{~mm}$ in maximum diameter) were made for each shape pattern. Measurement testing was conducted using 2 profile gauges and 3 repetitions for each specimen. A photograph of the outside shape was taken for each specimen for later verification.

Verification was performed by comparing the section modulus $(Z)$ as calculated of bitmap image determined from profile method and the one converted from the photograph of each specimen. The $Z$ values were numerically calculated from Eq. 9 by scanning the bitmap images $^{3}$.

$$
Z=\frac{\Sigma\left(y-\lambda_{1}\right)^{2} \mathrm{~d} A}{\max \left(\lambda_{1}, \lambda_{2}\right)}
$$

where $\quad \lambda_{1}=\frac{\Sigma y \mathrm{~d} A}{\Sigma \mathrm{d} A}, \quad \lambda_{2}=L_{\mathrm{y}}-\lambda_{1} \quad$ (see Fig. 5)

The bitmap images were rotated $0,45,90$, and 135 degrees and four $Z$ values were obtained. Then the four $Z$ values were averaged for each bitmap image.

Inspection for skew of the needle during drilling

In the case of a trunk with heartwood decay, the thickness of sound sapwood can be estimated using the drill resistance technique ${ }^{8}$. It is reported, however, that the fine drilling needle (with a shank diameter of $1.5 \mathrm{~mm}$ ) was apt to be skewed when drilling deep into the $\operatorname{wood}^{7,10}$. In 
that case, it may be difficult to obtain an accurate measurement of the sound xylem thickness. To better understand the skew of a drilling needle, a series of drilling tests was conducted. Specimens were cut from logs of Robinia pseudoacacia and Fraxinus excelsior (Table 1). It was considered that these species were apt to induce skew because of the high wood density and the large variations in density within a growth ring. The logs were approximately $500 \mathrm{~mm}$ long. Planks with a thickness of $50 \mathrm{~mm}$ and a width of $300 \mathrm{~mm}$, including pith cut from the logs, were held to the drilling device (IML-RESI F500) with clamps. The drill-holes were located at 3 points in a line $20 \mathrm{~mm}$ away from the end surface (Fig. 6). The drilling was conducted from bark-side surface along the radial direction toward the pith. After the test, the specimens were crosscut $40 \mathrm{~mm}$ from the end surface. Each specimen was sliced at $10 \mathrm{~mm}$ interval from the bark-side tangential face in order to follow the tracks of the drill holes. Deviations (absolute values) of the drill holes in longitudinal and tangential directions were measured for these 40 by $50 \mathrm{~mm}$ areas of sliced pieces. Then a 10-mm-thick specimen was crosscut from the rest of the plank in order to measure the moisture content at the drilling test.

The drilling test was conducted 3 times for each plank during conditioning of the moisture content from a moist condition to an air-dry condition in a humidity chamber.

Inspection for the effect of hollow size on section-modulus calculation

The inside hollow or heartwood decay reduces the section modulus and weaken the resistance to the stem breakage. Deep drilling will be necessary for the measurement of sound xylem thickness in the case of large-sized aged trees, which may result in the inaccurate evaluation of xylem thickness due to the skew of the drilling needle. However, the effect of a hollow located near the pith is known to be little. The effect of hollow size on the section modulus was inspected by numerical analysis ${ }^{3}$ using the bitmap images of shape patterns I-IV with hollows of 10 to $90 \%$ of the outside diameter.

\section{Results and Discussion}

The effects of shape patterns and specimen size on the error in section-modulus estimation

The ratio of the $Z$ value calculated for the generated image of the outside shape of specimens using the profile method to that calculated for the image converted from the photograph of the specimens were compared in terms of the condition of the shape patters and specimen size.

With regard to the shape-pattern difference, the error was comparatively large for patterns III and IV; the average $Z$ ratios were 1.03 (pattern III) and 0.96 (pattern IV) and the variations were rather large for those patterns. The gauge points required for patterns III and IV were greater than those for patterns I and II, especially with the use of $300 \mathrm{~mm}$ gauge (Table 2). The variations of the $Z$ ratios for which a $300 \mathrm{~mm}$ gauge was used were greater than those for 
which $900 \mathrm{~mm}$ gauge was used, except for pattern IV. These results suggest that the use of a short-span gauge to measure a complicated shape would require a number of gauge points and would generate a cumulative error in calculating the coordinates of the gauge points.

As regards the relationship between specimen size and error in $Z$ estimation, the variation was large for the specimen size of $1200 \mathrm{~mm}$ (Fig. 7). It was suspected that the number of gauge points had some effect on the accumulation of errors in coordinate calculation (Table 2). The variation for the $1200 \mathrm{~mm}$ specimen using a $300 \mathrm{~mm}$ gauge was greater than it was using a $900 \mathrm{~mm}$ gauge. On the other hand, the variation for the specimen size of $300 \mathrm{~mm}$ using a $900 \mathrm{~mm}$ gauge was greater than it was for a $300 \mathrm{~mm}$ gauge. This result may be attributed to the roughness of the profiling obtained using a $900 \mathrm{~mm}$ gauge for a 10-mm needle pitch compared with the specimen size.

The average $Z$ ratio for all conditions was 0.994 , which showed the high accuracy of $Z$ estimation achieved by the proposed profile method.

Skew of needle during drilling operation

The average moisture content in the 3 drilling test runs was 48, 22, and $13 \%$ and 49, 21, and 9\% for the Robinia and Fraxinus specimens, respectively. The drilling needle was skewed such that it stuck out from the plank surface in a number of the test runs. Because the stick-out of the needle was observed at a distance more than $210 \mathrm{~mm}$ from the bark-side edge, we addressed the trajectories of up to $210 \mathrm{~mm}$ for the test run that showed the maximum deviation among 3 drill holes (Fig. 8) and the average and maximum value of the deviation at a depth of $210 \mathrm{~mm}$ (Table 3 ).

There was no significant difference between the drill-hole deviation in the longitudinal and tangential directions at the depth of $210 \mathrm{~mm}$; $t$-value calculated from Student's $t$-test was 0.052. Although the difference in drilling resistance at deep portion has been observed between green wood and air-dry wood ${ }^{11}$, no difference in deviation was recognized between the moist condition (beyond the fiber saturation point) and air-dry condition ( $t$-value was 0.362). The maximum deviations at a depth of $210 \mathrm{~mm}$ were $12.5 \mathrm{~mm}$ for the longitudinal direction and $17.2 \mathrm{~mm}$ for tangential directions. In the case of a $20 \mathrm{~mm}$ deviation at a depth of $210 \mathrm{~mm}$, the secant gradient is $0.095 \mathrm{rad}$, so that the error in estimating the xylem thickness would be $0.5 \%$ which is negligible.

Effect of inside hollow on reduction in section modulus

The bitmap images of patterns I-IV with hollows, which have the same shape as the outside shape, of various sizes (10-100 percent in hollow/outside diameter ratio) in a concentric configuration to that of outside shape were made with image processing software. Then $Z$ values were calculated from Eq. 9 using the bitmap images. The ratios of $Z$ values with 
hollows of various sizes to that of solid shape for the patterns I-IV were shown in Fig. 9, where the difference between the outside diameter and hollow diameter was defined as the twice of the xylem thickness. The $Z$ ratios agreed well with the solid curve, which was calculated for the section modulus of a circular shaped tree trunk with a hollow $\left(Z_{\mathrm{H}}\right)$ using Eq. 11 .

$$
\begin{aligned}
& Z_{\mathrm{H}}=\frac{\pi}{32}\left\{\frac{D^{4}-(D-2 t)^{4}}{D}\right\} \\
& \frac{Z_{H}}{Z_{\mathrm{S}}}=1-\left(1-\frac{2 t}{D}\right)^{4}
\end{aligned}
$$

where $Z_{\mathrm{S}}$ is the section modulus of solid circular shape, $D$ is the diameter of a circular-shaped trunk, $t$ is the thickness of the xylem.

The reduction in $Z$ is calculated to be less than $5 \%$ when the xylem thickness is $26.4 \%$ or more of the trunk diameter. That is to say, the $Z$ values of trunks with inside hollow can be evaluated using the profile method together with the drill resistance technique on the condition that $26 \%$ of the trunk diameter could be drilled without skew.

\section{Conclusions}

1. Nondestructive estimation of the cross-sectional shape of tree trunks using a profile method was proposed. The section modulus of a cross section can be calculated from a generated binarized image.

2. The error in estimation of the section modulus of a tree trunk may be large to some extent for trunks with an irregular outside shape or a large diameter. Because of the cumulative error that accompanies an increase in the number of gauge points, a long profile gauge is recommended for use on large diameter trunks.

3. The deviation of the needle of the drilling device (IML-RESI F500) caused by skew was found to be less than $20 \mathrm{~mm}$ at a depth of $210 \mathrm{~mm}$; the error in the measurement of xylem thickness measurement would thus be negligible. The $Z$ values of trunks with inside hollow can be evaluated using the profile method together with the drill resistance technique on the condition that $26 \%$ of the trunk diameter could be drilled without skew.

\section{Acknowledgements}

The authors thank Mr. Masafumi Inoue for his kind assistance in the experimental work. This study was supported in part by JSPS KAKENHI (21580169). 


\section{References}

1. Peters M, Ossenbruggen P, Shigo A (1985) Cracking and failure behavior models of defective balsam fir trees. Holzforschung 39:125-135

2. Mattheck C, Kubler H (1995) Wood-the internal optimization of trees. Springer, Berlin

3. Koizumi A, Hirai T (2006) Evaluation of the section modulus for tree-stem cross sections of irregular shape. J Wood Sci 52(3):213-219

4. Habermehl A (1982) A new non-destructive method for determining internal wood condition and decay in living trees 1 . Arboricultural J 6:1-8

5. Watanabe $N$ (2000) Instruments available for tree diagnosis in the field (in Japanese). J Tree Health 4:23-32

6. Arita K, Mitani S, Sakai H, Tomikawa Y (1986) Inspection of internal decay in wooden poles using ultrasonic wave (in Japanese). Wood Industry 41:370-375

7. Iizuka Y (2007) Wood-decay diagnosis system (in Japanese). Tree and Forest Health 11:135-139

8. Rinn F, Schweingruber F-H, Schär E (1996) RESISTOGRAPH and X-ray density charts of wood Comparative evaluation of drill resistance profiles and X-ray density charts of different wood species. Holzforschung 50:303-311

9. Yada S (2001) Inspection and repair of exterior wood (in Japanese). Wood Industry $56: 452-457$

10. Fujii Y, Fujiwara Y, Harada M, Kigawa R, Komine Y, Kawanobe W (2009) Evaluation of insect attack in wooden historic buildings using drill resistance method (in Japanese). Hozon Kagaku 48:215-222

11. Yamashita K, Nagao H, Kato H, Ido H (2006) Estimating variations in wood density by drilling resistance (in Japanese). Bulletin of FFPRI 5:61-68 


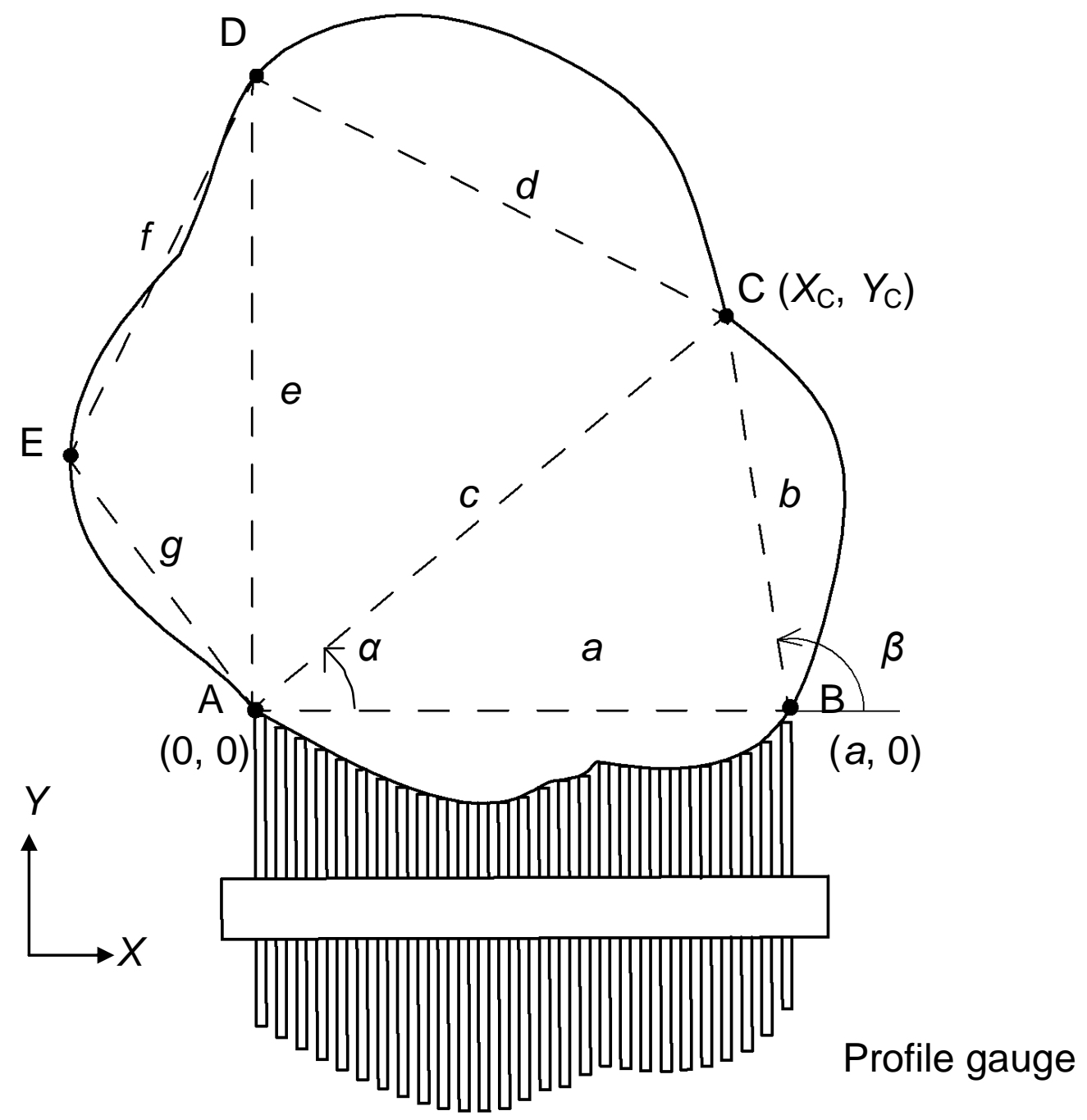

Fig. 1. Profile method for measurement of outside shape of a tree trunk 

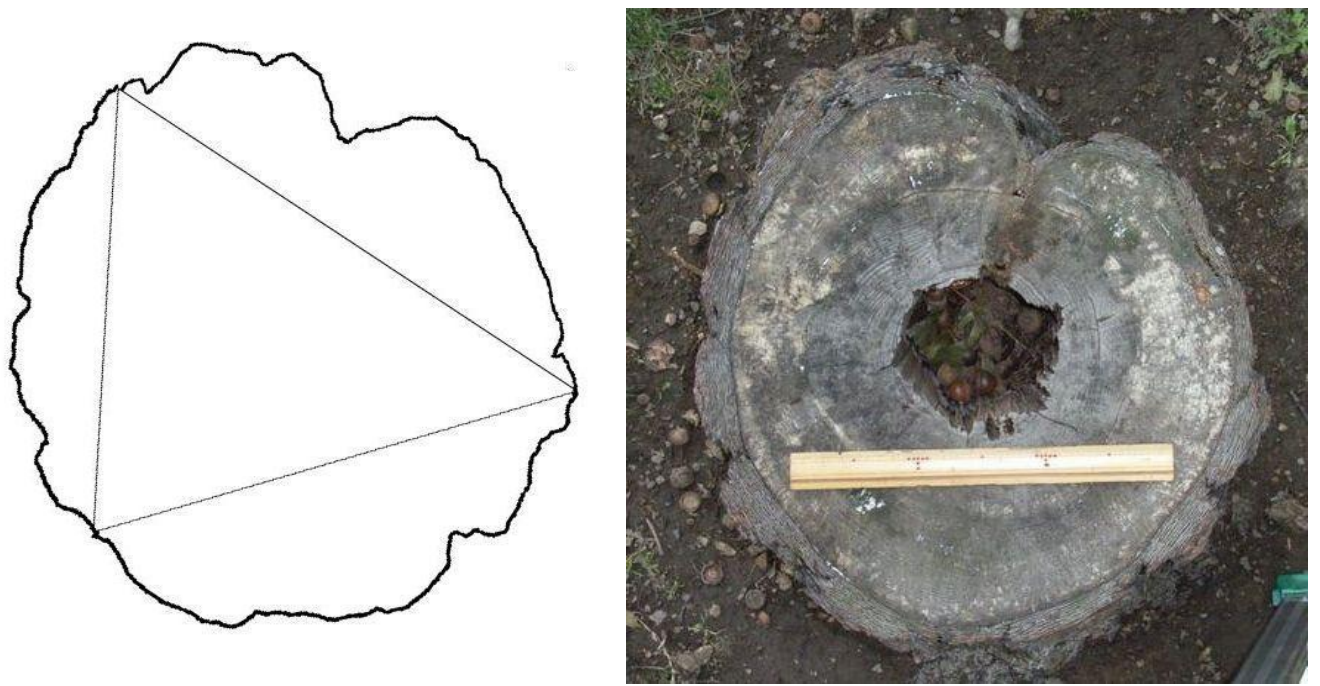

Fig. 2. An example of generated outside shape of a stump (left) and photograph (right) 


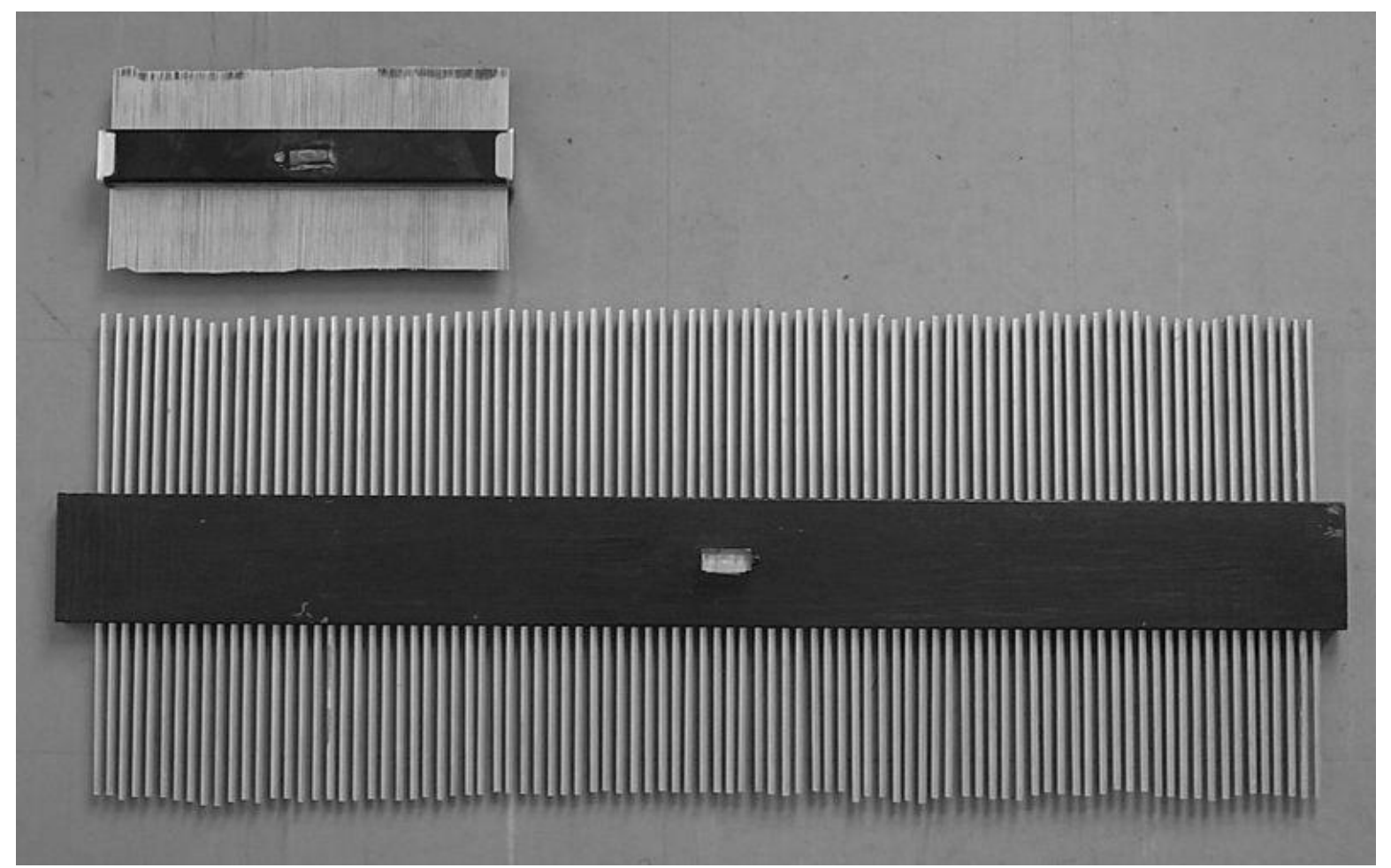

Fig. 3. Profile gauges: upper: 300-mm span with 1-mm pitch, lower: 900-mm span with 10-mm pitch 


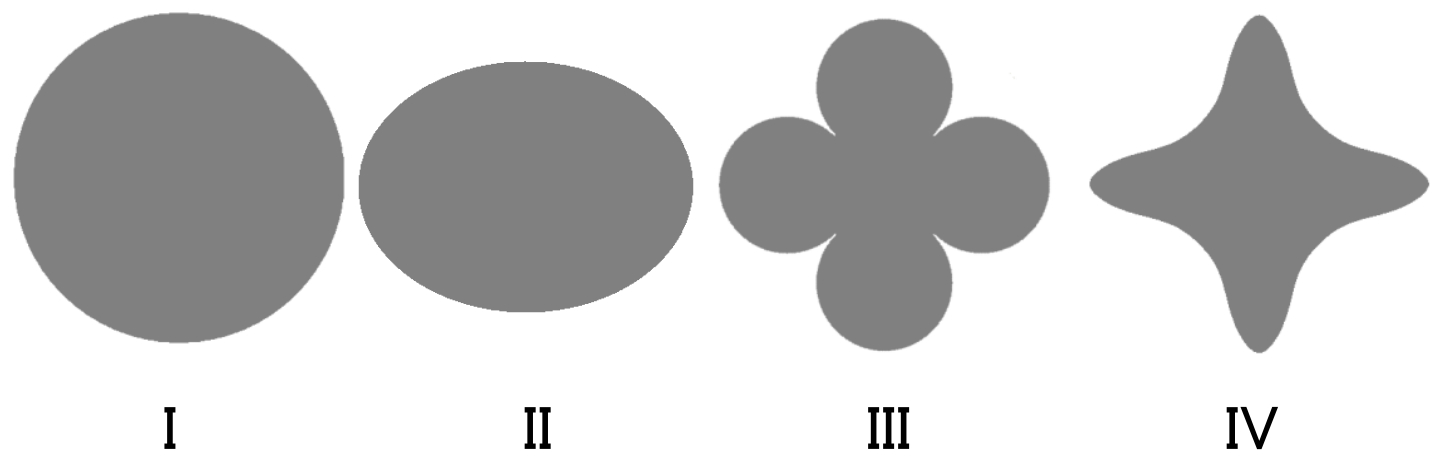

Fig. 4. Outside shape patterns of the specimens. Section moduli for pattern I, II, III, and IV in the case of $1 \mathrm{~m}$ in diameter were calculated as $0.0982,0.0553,0.0579$, and $0.0281 \mathrm{~m}^{3}$ from Eq. 9, respectively. 


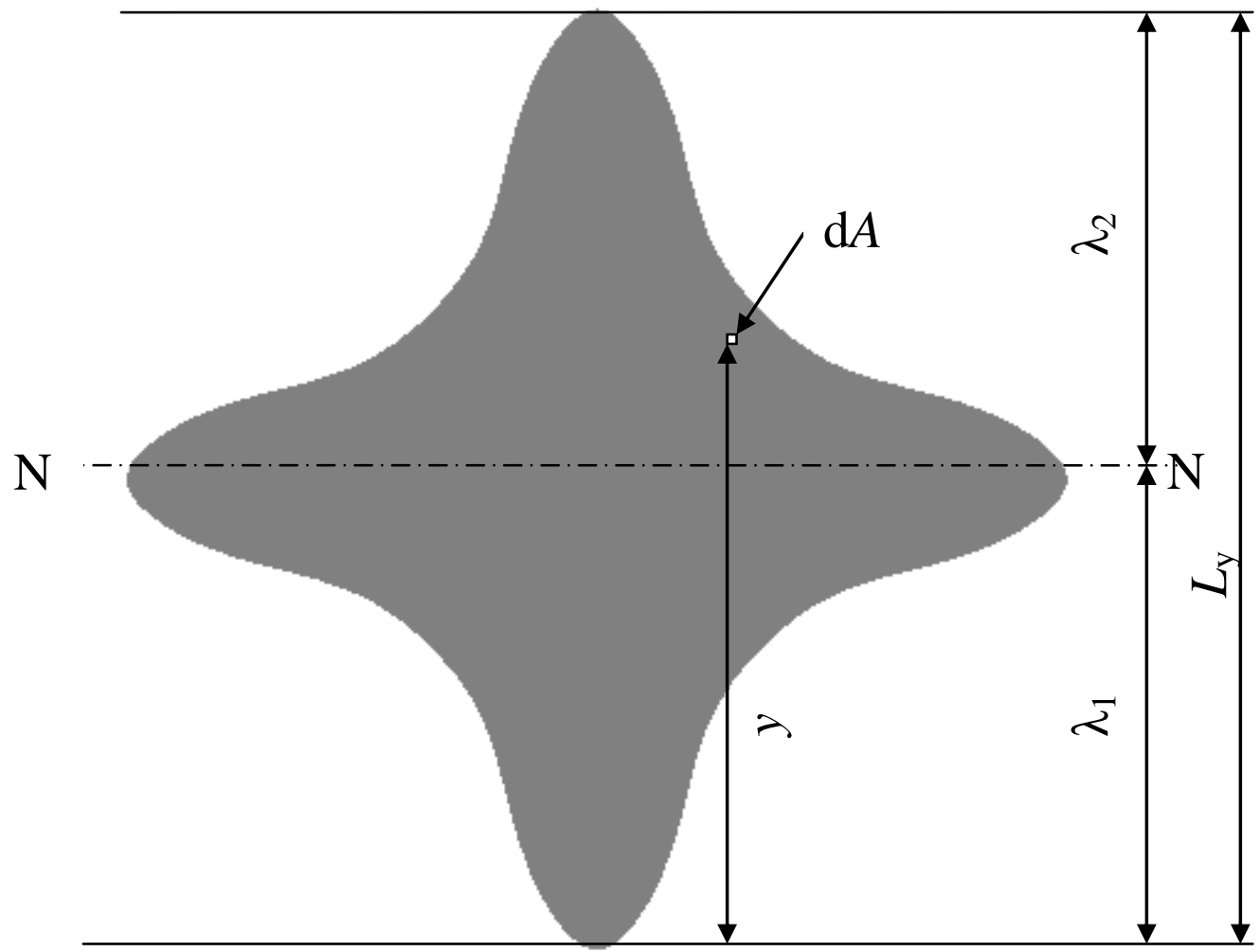

Fig. 5. Definitions used in calculation of section modulus $(Z) . \mathrm{N}-\mathrm{N}$ denotes neutral axis; $\mathrm{d} A$ is a pixel of the bitmap image 


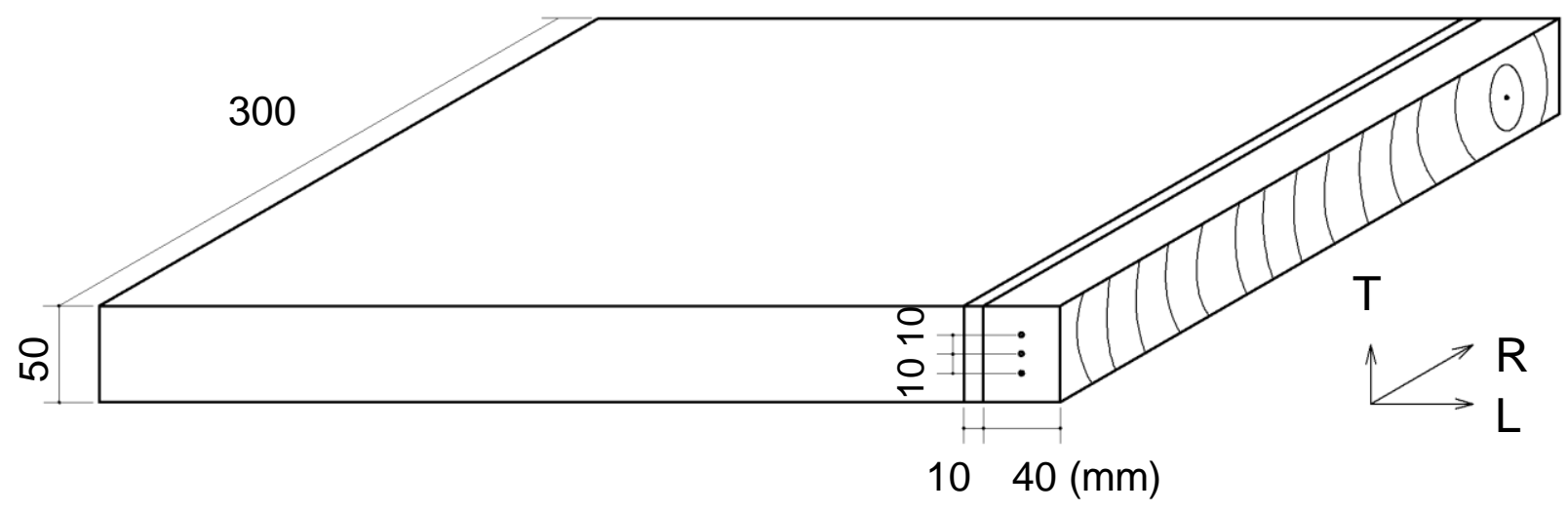

Fig. 6. Sample plank for inspecting skew of drilling needle. T, R, and L refer to the tangential, radial, and longitudinal directions, respectively 


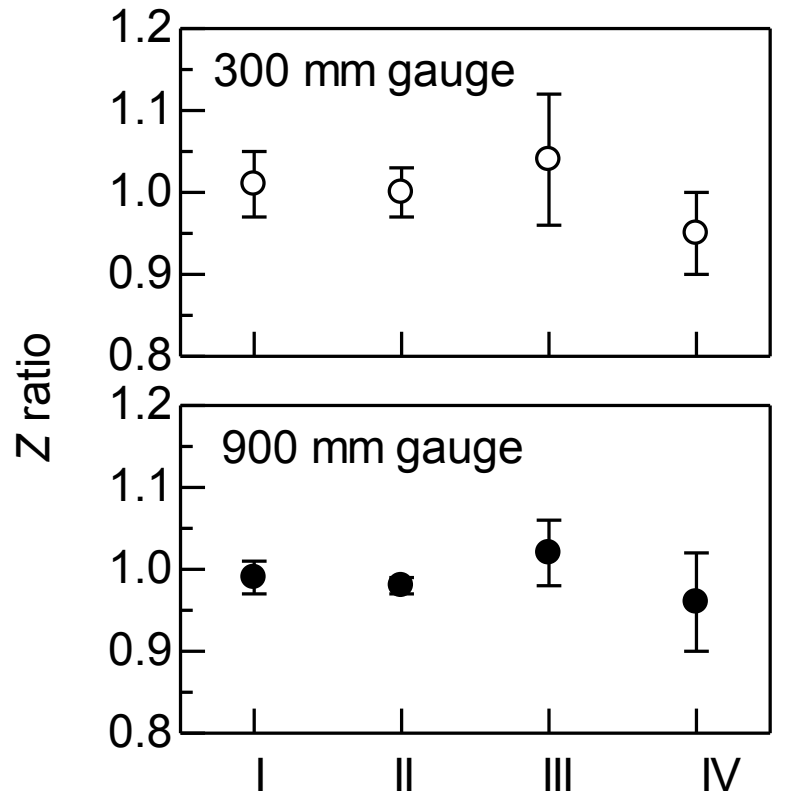

Shape pattern

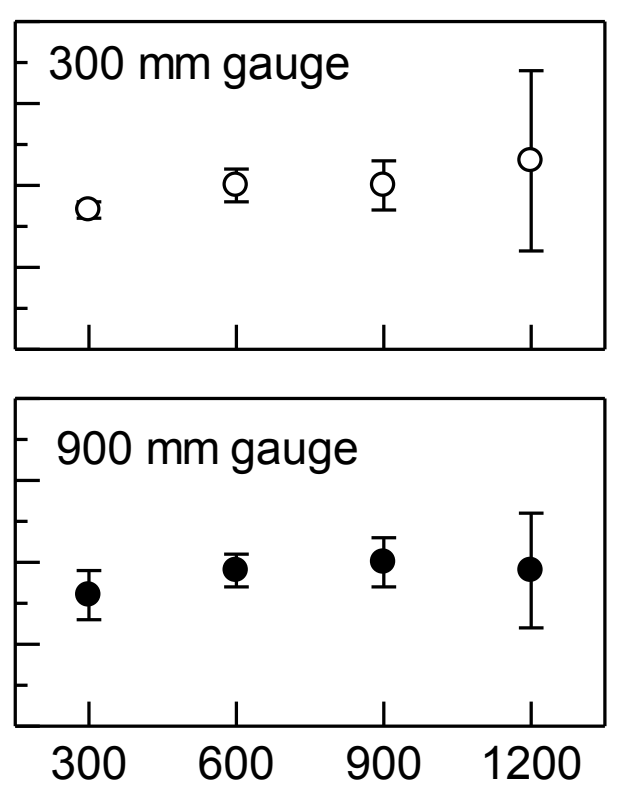

Specimen size $(\mathrm{mm})$

Fig. 7. $Z$ ratios for shape patterns and specimen sizes using $300-\mathrm{mm}-$ and 900 -mm-long profile gauges. $Z$ ratio is the ratio of section modulus calculated for the generated image using the profile method to that calculated for the image converted from the photograph. Error bars denote standard deviations 


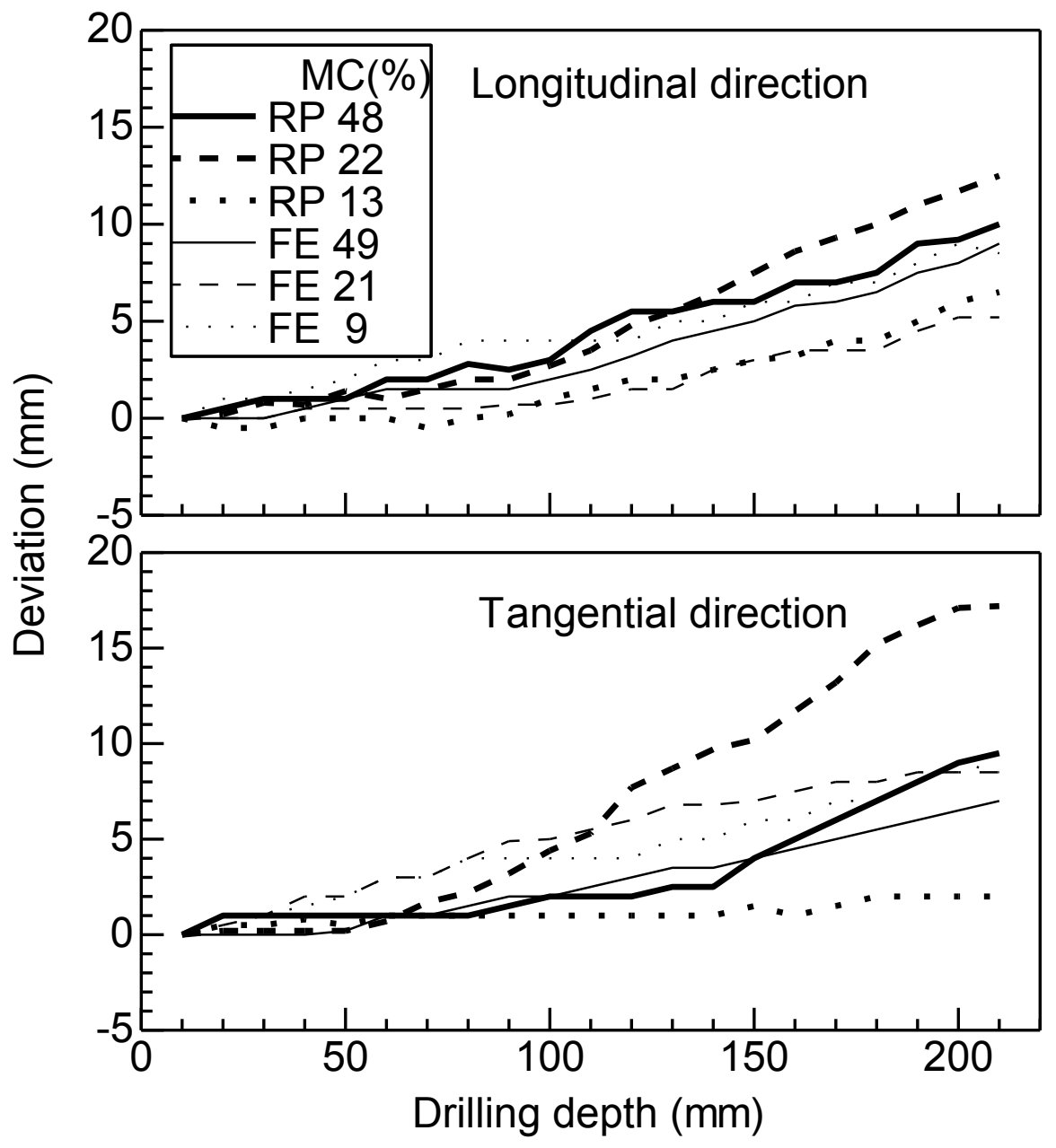

Fig. 8. Deviations of drilling hole associated with drilling depth for various moisture contents. RP, Robinia pseudoacacia; FE, Fraxinus excelsior 


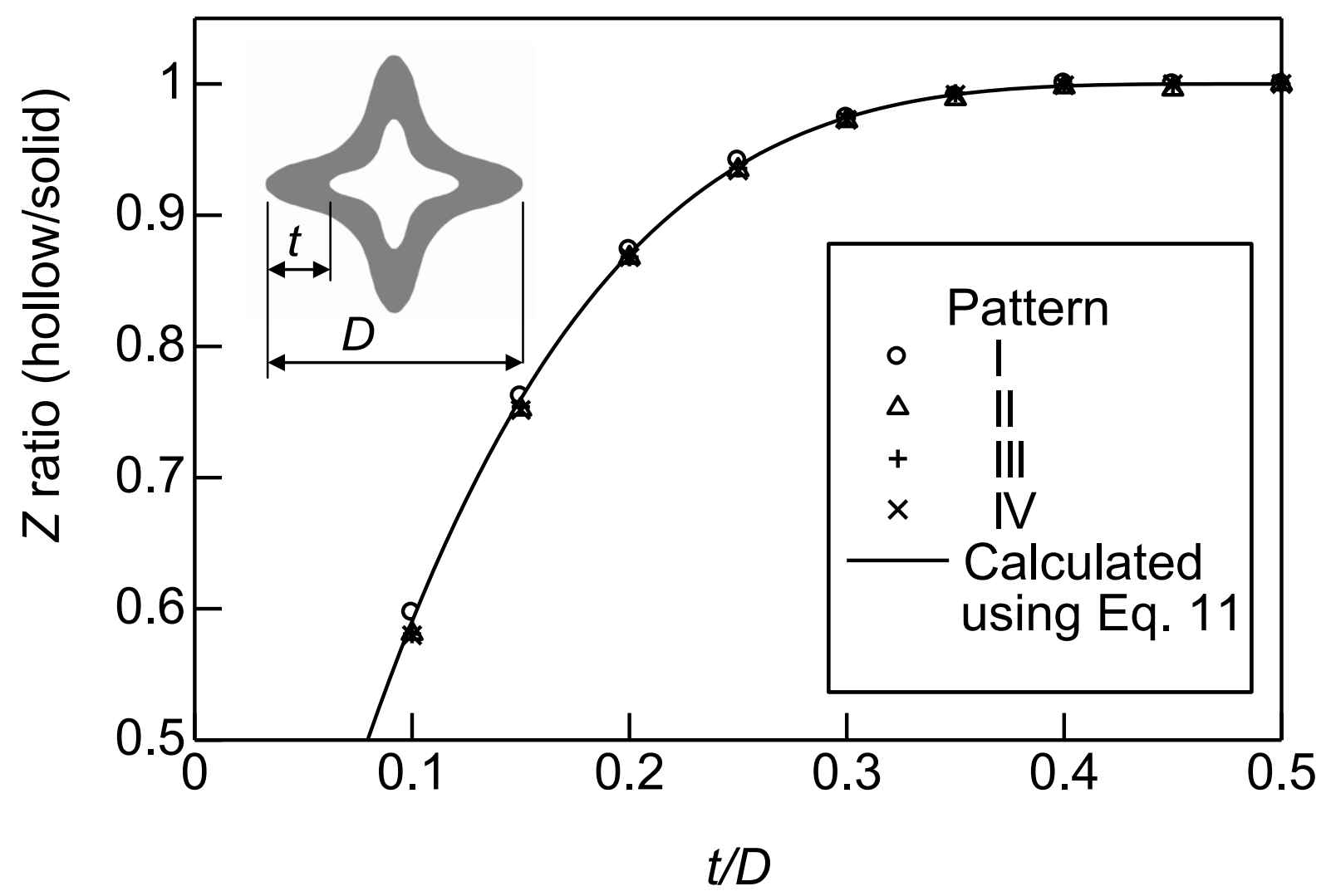

Fig. 9. Relationship between $t / D$ and $Z$ ratio. $t / D$ is the ratio of xylem thickness to trunk diameter. $Z$ ratio is the ratio of section modulus calculated for the image with a hollow to that calculated for the solid image. The shape illustrated in Fig. 9 shows an example of pattern IV with a hollow of 0.5 in hollow/outside diameter ratio; that is 0.25 in $t / D$ ratio 
Table 1. Wood density and average ring width of specimens for drilling test

\begin{tabular}{lccc}
\hline Species & $\begin{array}{c}\text { Log diameter } \\
(\mathrm{mm})\end{array}$ & $\begin{array}{c}\text { Air-dry density } \\
\left(\mathrm{kg} / \mathrm{m}^{3}\right)\end{array}$ & $\begin{array}{c}\text { Average ring width } \\
(\mathrm{mm})\end{array}$ \\
\hline RP & 826 & 724 & 11.4 \\
FE & 950 & 701 & 8.8 \\
\hline
\end{tabular}

RP, Robinia pseudoacacia; FE, Fraxinus excelsior 
Table 2. Number of required gauge points for test conditions

\begin{tabular}{|c|c|c|c|c|c|c|c|c|}
\hline \multirow{2}{*}{$\begin{array}{l}\text { Specimen } \\
\text { size }(\mathrm{mm})\end{array}$} & \multicolumn{2}{|c|}{ Pattern I } & \multicolumn{2}{|c|}{ Pattern II } & \multicolumn{2}{|c|}{ Pattern III } & \multicolumn{2}{|c|}{ Pattern IV } \\
\hline & 300 & 900 & 300 & 900 & 300 & 900 & 300 & 900 \\
\hline 300 & 3 & 3 & 3 & 2 & 4 & 4 & 4 & 2 \\
\hline 600 & 6 & 3 & 5 & 2 & 8 & 4 & 8 & 2 \\
\hline 900 & 10 & 3 & 8 & 3 & 12 & 4 & 10 & 4 \\
\hline 1200 & 13 & 4 & 12 & 4 & 16 & 5 & 12 & 4 \\
\hline Average & 8.0 & 3.3 & 7.0 & 2.8 & 10.0 & 4.3 & 8.5 & 3.0 \\
\hline
\end{tabular}

Patterns I-IV are shown in Fig. 4. The values of 300 and 900 beneath the pattern numbers are the length of the profile gauges in $\mathrm{mm}$ 
Table 3. Skew deviation of the drilling needle at a depth of 210 $\mathrm{mm}$ from bark-side surface

\begin{tabular}{lrrrrrr}
\hline \multirow{2}{*}{ Species } & $\mathrm{mc}(\%)$ & \multicolumn{2}{c}{ Deviation-L $(\mathrm{mm})$} & & \multicolumn{2}{c}{ Deviation- $\mathrm{T}(\mathrm{mm})$} \\
\cline { 3 - 4 } \cline { 6 - 7 } & & Average & Maximum & & Average & Maximum \\
\hline RP & 48 & 6.3 & 10.0 & & 5.0 & 9.5 \\
RP & 22 & 9.1 & 12.5 & & 10.6 & 17.2 \\
RP & 13 & 4.8 & 6.5 & & 1.0 & 2.0 \\
FE & 49 & 6.3 & 9.5 & & 4.2 & 7.0 \\
FE & 21 & 3.7 & 5.2 & & 7.8 & 8.5 \\
FE & 9 & 5.7 & 8.5 & & 4.2 & 7.0 \\
\hline
\end{tabular}

RP, Robinia pseudoacacia; FE, Fraxinus excelsior.

Deviation-L and -T denotes the skew (absolute value) in the

longitudinal and tangential direction, respectively (see Fig. 6). mc, moisture contents 